\title{
BMJ Open Mental health selection: common mental disorder and migration between multiple states of deprivation in a UK cohort
}

\author{
Giles Greene (D) , ${ }^{1}$ Andrea Gartner, ${ }^{1}$ Daniel Farewell, ${ }^{1}$ Lazlo Trefan, ${ }^{1}$ \\ Alisha R Davies, ${ }^{2}$ Mark A Bellis, ${ }^{2}$ Shantini Paranjothy ${ }^{1}$
}

To cite: Greene G, Gartner A, Farewell D, et al. Mental health selection: common mental disorder and migration between multiple states of deprivation in a UK cohort. BMJ Open 2020;10:e033238. doi:10.1136/ bmjopen-2019-033238

- Prepublication history and additional material for this paper are available online. To view these files, please visit the journal online (http://dx.doi. org/10.1136/bmjopen-2019033238).

Received 31 July 2019 Revised 23 December 2019 Accepted 13 January 2020

\section{Check for updates}

(c) Author(s) (or their employer(s)) 2020. Re-use permitted under CC BY-NC. No commercial re-use. See rights and permissions. Published by BMJ.

${ }^{1}$ Division of Population Medicine, School of Medicine, Cardiff University, Cardiff, UK

${ }^{2}$ Policy, Research and International Development, Public Health Wales, Cardiff, UK

Correspondence to

Dr Giles Greene;

greeneg@cardiff.ac.uk

\section{ABSTRACT}

Objectives To assess whether the direction of movement along the social gradient was associated with changes in mental health status.

Design Longitudinal record-linkage study using a multistate model.

Setting Caerphilly, Wales, UK between 2001 and 2015.

Participants The analytical sample included 10892

(60.8\% female) individuals aged $18-74$ years.

Primary and secondary outcome measures Deprivation change at lower super output area level using the 2008 Welsh Index of Multiple Deprivation. Mental health was assessed in 2001 and 2008 using the Mental Health Inventory subscale of the short-form 36 V.2.

Results Mental health selection was shown whereby individuals with common mental health disorders were less likely to move to areas of lower deprivation but more likely to move to areas of greater deprivation.

Conclusion Poor mental health seems to drive health selection in a similar way to poor physical health. Therefore, funding targeted at areas of higher deprivation should consider the demand to be potentially higher as individuals with poor mental health may migrate into that area.

\section{INTRODUCTION}

The wider social, economic and environmental determinants of poor mental health tend to be associated with the areas of greatest deprivation. ${ }^{1-3}$ The question often posed is, to what extent does migration explain underlying geographical differences in health. People with better health differentially migrate towards areas of lower deprivation leaving a greater proportion of those in poorer health living in disadvantaged areas. $^{4-6}$ This health selection systematically distributes people between deprivation levels, ${ }^{7}$ however, there is no consensus as to whether this selection could potentially increase spatial inequalities in health.

The reasons for these disparities may lie in the differing study designs, settings, geographic scales as well as the data sources
Strengths and limitations of this study

- Use of representative and well-designed baseline survey data on 10892 subjects at two time points and 15 years record-linked follow-up data.

- Migration coded solely from administrative datasets allowing for more accurate, time-varying description of migration.

- Covariates were measured at fixed time points increasing the risk of misclassification.

- Non-response between the two waves was multiplicative, and those responding twice were more likely to be healthier and wealthier.

and specific outcomes measures. Health outcomes such as self-reported limiting long-term illness or general and psychological health ${ }^{8-11}$ may confound or mediate the relationship between migration and deprivation. In addition, age is a driver of migration with widening of inequalities in self-reported health being driven by those in middle age moving to areas of less deprivation. ${ }^{12}$ Younger people may move for work or study, or to set up a family home, and tend to be healthier. Older people may move to live nearer family or to access care due to poor health. ${ }^{13}$

The most widely known health selection phenomenon is the 'healthy migrant effect'.

This usually refers to the movement of individuals between countries, who are generally economic immigrants and tend to be younger and physically and psychologically healthier. ${ }^{1415}$ Although there is an established international effect, a similar effect relating to internal migration is emerging. Generally, internal migration is more complex and likely to be motivated by differing factors. An aspirational move up by those younger and healthier may be as likely as a move down due to worsening health or change in circumstance. Therefore, internal migration needs 
to consider where one starts and finishes, ${ }^{16}$ the distance moved $^{1718}$ and/or reasons for moving. ${ }^{1118-20}$ The effects of this differential migration are hard to measure in the short term as residential deprivation is not significantly changed by short-term mobility. ${ }^{21}$ Migration between deprivation fifths in the years preceding death was shown to not have altered health inequalities substantially, ${ }^{13}$ but the trajectory may be determined earlier in life.

\section{Mental health selection}

Mental health selection refers to the differential likelihood of moving between deprivation quintiles due to differences in psychological health. ${ }^{22}$ Most studies exploring the role of mental health and migration focus on the impact on mental health from migration, rather than the role of mental health contributing to a move. ${ }^{23}{ }^{24}$ To this end, a meta-analysis found that levels of common mental disorders within migrant communities were not associated with migration. ${ }^{25} 26$ In relation to the likelihood of migration, poorer mental health in men was associated with a movement to areas of greater deprivation compared with those who were geographically stable. ${ }^{27} \mathrm{~A}$ few recent studies assessed the association between mental health and migration, including the role of mental health as a reason to move. ${ }^{28-30}$

In contrast to physical health, which tended to be better for those who move, poor mental health was more prevalent in movers compared with non-movers, particularly in those who moved to socioeconomically deprived areas. $^{21} 31$ People with poorer mental health were less likely to have their 'residential mobility preference' met, defined either by a move despite indicating not intending to move at baseline or not having achieved a desired move on follow-up a year later. ${ }^{16}$ In addition, people with mental health problems tend to 'drift' towards poor, socially disadvantaged areas. ${ }^{31}$ Others have argued that the reasons for a move, positive or negative, should be considered in any analysis, although these data are rare. Difficult life events (relationship breakdown, housing eviction, job loss) can influence health characteristics of migrants and their 'sociospatial trajectories', reducing the likelihood of moves to less deprived areas among people with mental illness. ${ }^{11}$ This may therefore contribute to geographical inequalities by resulting in higher concentrations of people with mental health problems in more deprived areas. ${ }^{11}$

We have previously shown that poor physical health was associated with a move to an area of greater deprivation. ${ }^{13}$ The present study seeks to expand on this and to examine whether the direction of movement along the social gradient was associated with differences in mental health. To ascertain the changes in exposure to area-level deprivation, quintiles of the Welsh Index of Multiple Deprivation (WIMD), ${ }^{32}$ a multistate model (MSM), was used allowing individuals to move between WIMD quintiles using data from a community study of health inequality set in the county borough of Caerphilly, south-east Wales.

\section{METHODS}

We have previously described the prospective cohort study, the Caerphilly Health and Social Needs Electronic Cohort Study in detail. ${ }^{33}$ Briefly, in 2001 a stratified random sample of 22236 individuals aged 18 years and over resulted in 10892 respondents to a baseline postal questionnaire survey, of whom 10170 provided valid information on mental health. In 2008, the survey was repeated, sampling the 9551 participants who still resided in the borough. Of these, 4558 participants responded of whom 4426 provided a valid mental health score. The analytical sample consisted of 10 892, with time-varying mental health and other covariates for those responding at both waves (see online supplementary figure S1 for the Consolidated Standards of Reporting Trials diagram).

\section{Patient and public involvement}

This is a secondary analysis of previously collected and administrative data. There was no patient involvement in this analysis.

\section{Data linkage}

The survey data were linked in the Secure Anonymised Information Linkage (SAIL) databank, available through Health Data Research UK at the College of Medicine, Swansea University $^{34} 35$ to the Welsh Demographic Service (WDS) dataset and the Office for National Statistics mortality files to create the electronic cohort with a 15-year follow-up period. The WDS contains the unique National Health Service (NHS) number for all individuals who register with a general practitioner, from which an anonymised linking field was generated for use as the primary key variable for record-linkage. Those in the study population were included in the WDS at the start and either remained in Wales for the study period or were censored as they died or moved out of wales. Participants who moved out of Wales and then returned re-entered the study. The time in the study was calculated based on time in Wales. ${ }^{33}$ The electronic cohort was established to allow further analysis using all routinely collected primary and secondary care data, however, the present study only used the demographic function to follow-up on migration.

\section{Outcome measure}

The outcome of interest was self-reported mental health assessed via survey questionnaire at two points in time using the Mental Health Inventory (MHI-5) subscale of the short-form 36 (SF-36) V.2, and not through NHS data linkage. The MHI-5 has been shown to be a robust measure of the common mental disorders of anxiety and depression in the general adult population. ${ }^{36}$ We defined a binary variable of case/non-case of common mental disorder (CMD) using a cut-point on the scale of $\leq 60$. $^{37}$

\section{Transitions in deprivation}

Change in deprivation was calculated at lower super output level (LSOA) using the WIMD 2008. ${ }^{32}$ Participants' residence, aggregated to LSOA level, at any time during the study period is recorded in the WDS, which was linked 
to deprivation quintiles based on the published ranks. We coded deprivation change as a move to a different deprivation quintile or staying, either not moving or a move within the same quintile.

\section{Neighbourhood cohesion}

The questionnaire included a module on perceptions of the local neighbourhood, including the Neighbourhood Cohesion Scale. ${ }^{38}$ We have previously described in detail the properties of this scale in an econometric analysis. ${ }^{39}$ The scale comprises questions measuring cognitive aspects of social cohesion characterised by trust and reciprocity and neighbourhood attachment, characterised by feelings of belonging and a sense of community. Questionnaire responses were to a 5-point Likert scale of 1 strongly agree, 2 agree, 3 neither agree or disagree, 4 disagree and 5 strongly disagree to the question stem of "How much do you agree with the following statements about your neighbourhood?" We summed the responses to the 15 items in the scale with reverse coding where appropriate and equal weighting to create a neighbourhood score with a range of possible scores between 15 and 75 .

\section{Individual-level socioeconomic and other variables}

The dataset included information on age, coded in 10-year bands; gender; migration status (defined as a move at any time during the study period); Registrar General Social Class (I and II, III non-manual, III manual, IV and V, other); employment status (employed, seeking work, student, home/carer, permanently sick or disabled, retired); housing tenure (owner-occupier or not); council tax band (A (lower property value), B, C, D, $\mathrm{E}, \mathrm{F}-\mathrm{H}$ (higher property value), $\mathrm{F}-\mathrm{H}$ (combined due to small numbers)); gross household income, dichotomised above and below the UK definition of poverty of $60 \%$ of median income (National Statistics, Department for Work and Pensions, 2011); smoking status (daily, occasional but not every day, used to, never smoked) and physical health (quartiles derived from the physical component score from the SF-36).

\section{Analysis}

All analyses were performed in the secure SAIL gateway using Stata V. $15^{40}$ and R. ${ }^{41}$ We first derived descriptive statistics for the demographic, socioeconomic, health status and perception of neighbourhood variables. We described the proportions for the covariates across the WIMD quintiles (table 1) with column percentages describing the distribution of individuals within WIMD quintiles across the covariate groupings. We also tested for trend using 'nptrend' in Stata. Trends were defined by differences in the proportions across WIMD quintiles grouped by the categorical covariates. The sample population consisted of $10836(56(0.5 \%)$ of the sample could not be matched to WIMD quintile) individuals. All individuals had at least one observation of their mental health, while 4426 people had two mental health observations. The model then tested the association between their one

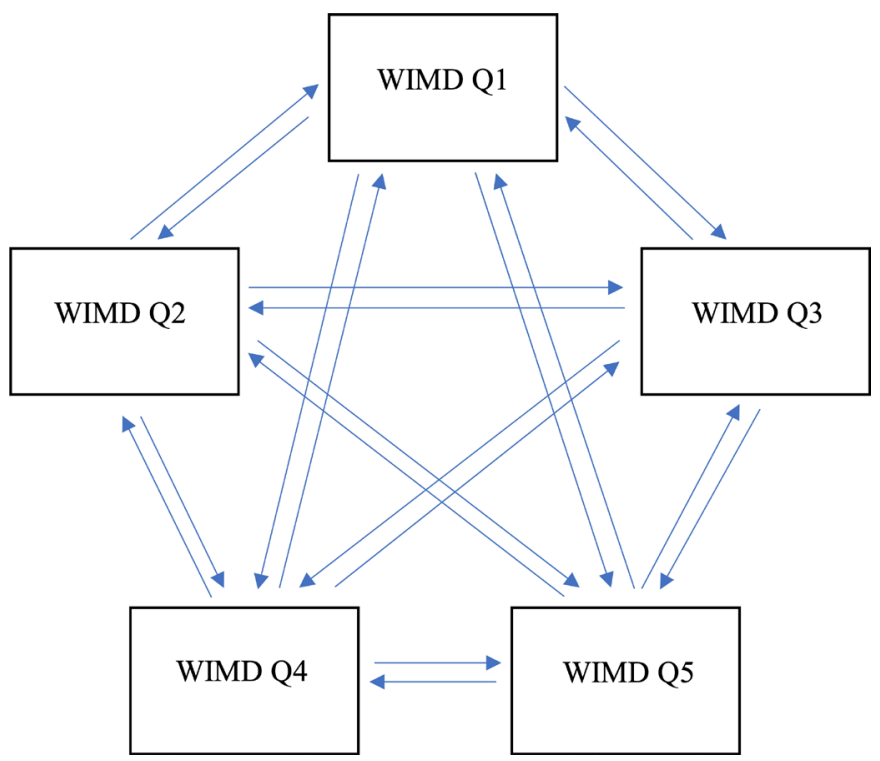

Figure 1 Representation of possible transitions between Welsh Index of Multiple Deprivation (WIMD) quintiles (1=least deprived, $5=$ most deprived).

or both observed mental health state and their subsequent moves. WIMD quintiles were known for each move. There were a total of 21168 moves ranging between 1 and 12 per person over the 15-year study period from 2001 to 2016. An initial analysis tested and found no interaction between gender and age, therefore further analyses were not undertaken separated by gender or age group.

To estimate the effect of migration between and within WIMD quintiles, an MSM was used. An MSM is defined as a model for a random process, which at any time occupies one of a set of discrete states. The state structure specifies the states and which transitions from state to state are possible. MSMs use Markov processes, whereby for an observed state, a future state depends on the present state, but not on earlier states. ${ }^{42}$ In an MSM, the transition intensities provide the hazards for movement from one state to another.

The MSM method counters any potential ceiling and floor effects, as they explicitly and naturally condition on the current state occupied so that, for example, the chance of a positive increment is zero if an individual is already in the 'uppermost' state. By contrast, incorporating such dependence on current state into traditional linear (say) models is challenging, because the expected increment must change both its mean and its variance to reflect the structural knowledge that a positive increment is impossible.

The present MSM used the five exclusive WIMD quintile states (figure 1). Coefficients, representing the risk of moving from one state to another, were computed using the maximum likelihood method. The modelling included the covariates of gender, age group (in 10-year bands), neighbourhood cohesion, social class, employment status, housing tenure, council tax band, poverty status and physical health. The model was fitted using $\mathrm{R}$ 
Table 1 Numbers and column percentages of 10836 participants in WIMD categories stratified by covariates at baseline

\begin{tabular}{|c|c|c|c|c|c|c|}
\hline & \multicolumn{5}{|c|}{ Deprivation quintile } & \multirow[b]{2}{*}{$\begin{array}{l}P \text { for } \\
\text { trend }\end{array}$} \\
\hline & $\begin{array}{l}\text { First-least } \\
\text { deprived }\end{array}$ & Second & Third & Fourth & $\begin{array}{l}\text { Fifth-most } \\
\text { deprived }\end{array}$ & \\
\hline $\mathrm{N}$ & 808 & 1114 & 2267 & 3582 & 3065 & \\
\hline Gender & & & & & & 0.892 \\
\hline Female & $441(54.31)$ & $613(54.83)$ & $1232(54.04)$ & $1995(55.46)$ & $1734(56.23)$ & \\
\hline Male & $371(45.69)$ & $505(45.17)$ & $1048(45.96)$ & $1602(44.54)$ & $1350(43.77)$ & \\
\hline Age (years) & & & & & & 0.037 \\
\hline $18-24$ & $48(5.91)$ & $76(6.8)$ & $170(7.46)$ & $296(8.23)$ & $287(9.31)$ & \\
\hline $25-34$ & $134(16.5)$ & $176(15.74)$ & $360(15.79)$ & $563(15.65)$ & 487 (15.79) & \\
\hline $35-44$ & $173(21.31)$ & $237(21.2)$ & $444(19.47)$ & $687(19.1)$ & 576 (18.68) & \\
\hline $45-54$ & $183(22.54)$ & 249 (22.27) & 509 (22.32) & $748(20.8)$ & 635 (20.59) & \\
\hline $55-64$ & $151(18.6)$ & $228(20.39)$ & 433 (18.99) & $686(19.07)$ & $568(18.42)$ & \\
\hline $65-74$ & $123(15.15)$ & $152(13.6)$ & $364(15.96)$ & $617(17.15)$ & $531(17.22)$ & \\
\hline Migrate $^{*}$ & & & & & & $<0.001$ \\
\hline Stay & $1197(63.00)$ & $1628(68.46)$ & 3255 (73.26) & $5018(75.20)$ & 4238 (73.39) & \\
\hline Move & $703(37.00)$ & $750(31.54)$ & $1188(26.74)$ & $1655(24.80)$ & $1537(26.61)$ & \\
\hline Common mental health disorder & & & & & & $<0.001$ \\
\hline Negative & $639(79.08)$ & $790(72.08)$ & 1579 (70.59) & $2372(67.62)$ & $1777(59.17)$ & \\
\hline Positive & 169 (20.92) & $306(27.92)$ & $658(29.41)$ & $1136(32.38)$ & $1226(40.83)$ & \\
\hline \multicolumn{7}{|l|}{ Missing $†$} \\
\hline Neighbourhood cohesion & & & & & & $<0.001$ \\
\hline Low & $180(22.17)$ & $283(25.31)$ & $613(26.89)$ & $1070(29.75)$ & $1124(36.45)$ & \\
\hline Medium & $264(32.51)$ & 375 (33.54) & $709(31.1)$ & $1063(29.55)$ & $844(27.37)$ & \\
\hline High & $337(41.5)$ & $386(34.53)$ & $788(34.56)$ & $1126(31.3)$ & $797(25.84)$ & \\
\hline Missing & $31(3.82)$ & $74(6.62)$ & $170(7.46)$ & $338(9.4)$ & $319(10.34)$ & \\
\hline Social class & & & & & & $<0.001$ \\
\hline I and II & $321(39.53)$ & $318(28.44)$ & $593(26.01)$ & $743(20.66)$ & $444(14.4)$ & \\
\hline III non-manual & $189(23.28)$ & $252(22.54)$ & $508(22.28)$ & $654(18.18)$ & $518(16.8)$ & \\
\hline III manual & $123(15.15)$ & $222(19.86)$ & $454(19.91)$ & 767 (21.32) & 639 (20.72) & \\
\hline IV and V & $119(14.66)$ & $226(20.21)$ & $505(22.15)$ & $919(25.55)$ & $928(30.09)$ & \\
\hline Other & $25(3.08)$ & $42(3.76)$ & $102(4.47)$ & $222(6.17)$ & $281(9.11)$ & \\
\hline Missing & $35(4.31)$ & $58(5.19)$ & $118(5.18)$ & $292(8.12)$ & $274(8.88)$ & \\
\hline Employment & & & & & & $<0.001$ \\
\hline Employed & 509 (62.68) & $642(57.42)$ & $1257(55.13)$ & $1844(51.26)$ & $1294(41.96)$ & \\
\hline Seeking work & $18(2.22)$ & 29 (2.59) & 45 (1.97) & $83(2.31)$ & $114(3.7)$ & \\
\hline Student & $14(1.72)$ & $24(2.15)$ & $52(2.28)$ & $56(1.56)$ & $44(1.43)$ & \\
\hline Carer & $43(5.3)$ & $58(5.19)$ & $144(6.32)$ & $258(7.17)$ & 308 (9.99) & \\
\hline Sick & $41(5.05)$ & $89(7.96)$ & 227 (9.96) & $438(12.18)$ & $521(16.89)$ & \\
\hline Retired & $167(20.57)$ & 242 (21.65) & $465(20.39)$ & $711(19.77)$ & 604 (19.58) & \\
\hline Missing & $20(2.46)$ & $34(3.04)$ & 90 (3.95) & $207(5.75)$ & $199(6.45)$ & \\
\hline Tenure & & & & & & $<0.001$ \\
\hline Owner occupier & 49 (6.03) & $75(6.71)$ & $230(10.09)$ & $653(18.15)$ & $1003(32.52)$ & \\
\hline Not owner occupier & 751 (92.49) & $1029(92.04)$ & $2026(88.86)$ & $2876(79.96)$ & $2020(65.5)$ & \\
\hline Missing & $12(1.48)$ & $14(1.25)$ & $24(1.05)$ & $68(1.89)$ & $61(1.98)$ & \\
\hline Council tax band & & & & & & $<0.001$ \\
\hline
\end{tabular}


Table 1 Continued

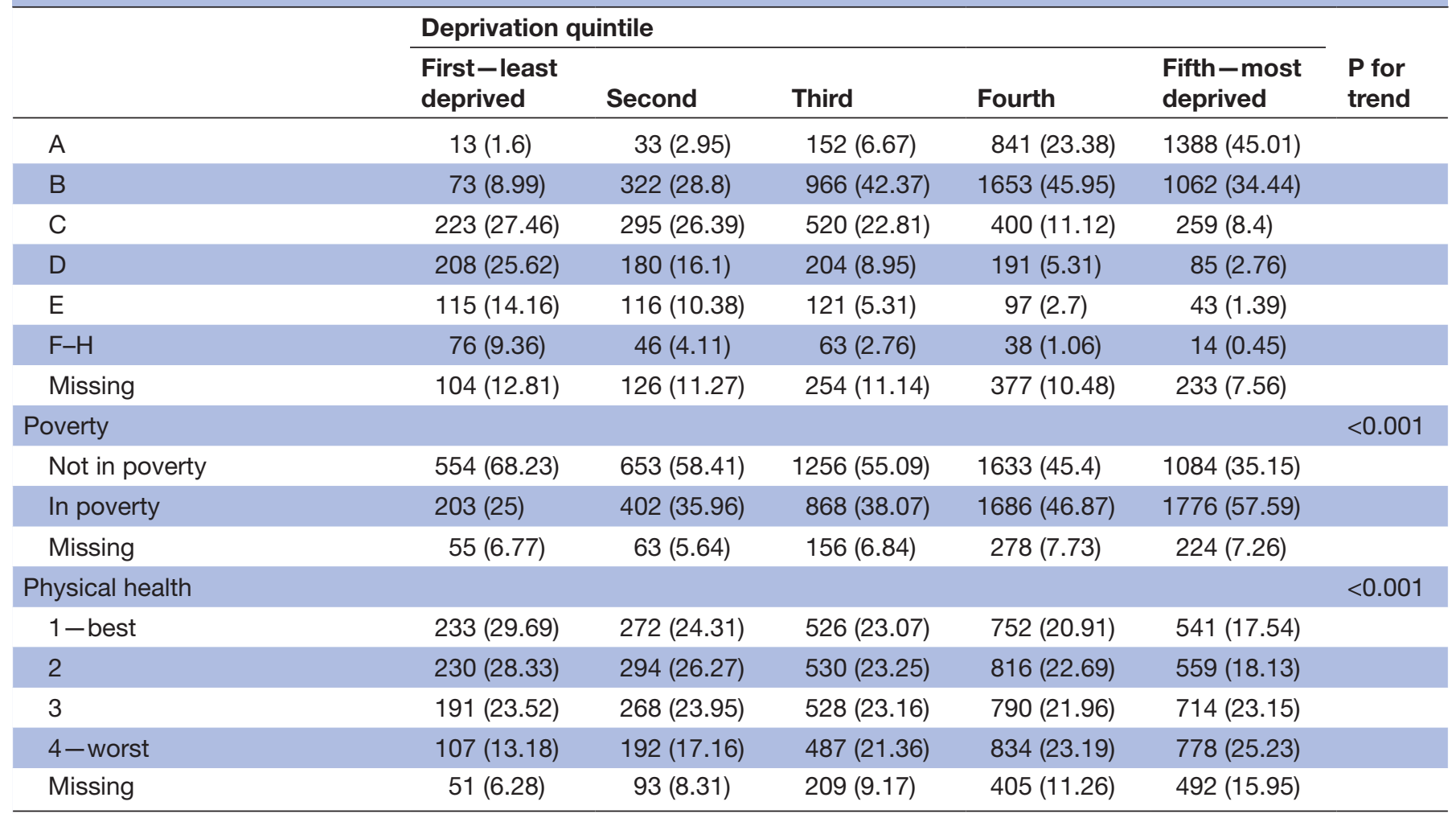

All covariates demonstrate a strong trend except for age and gender.

*Total moves over study period, n=21 169.

†Category removed due to small numbers.

WIMD, Welsh Index of Multiple Deprivation.

V.3.5.0 software, ${ }^{41}$ and the 'msm' package V.1.6.6. ${ }^{43}$ Missingness within the data ranged between $12 \%$ and $<1 \%$, however standard multiple imputation methods are very difficult to carry out for MSMs when the observed data contain longitudinal response data with random lengths and unequal spaces. ${ }^{44}$ Therefore, to minimise the likelihood of this we included the missing categories for the covariates in the analysis (for comparison of association with mental health at baseline with missing categories vs imputed data, see the online supplementary appendix).

\section{RESULTS}

Table 1 shows a general trend of social disadvantage whereby those in areas of greater deprivation (higher WIMD quintiles) are less likely to be employed, more likely to be in poverty, experience worse mental health and lower social cohesion. The number and direction of transitions shown in table 2 suggest that the majority of individuals either did not move or moved within the same WIMD quintile and that move likelihood was inversely correlated with WIMD differential. Table 3 shows the likelihood of suffering from a common mental health disorder for those who moved. Each transition is examined while holding all covariates as well as all information on those who either moved or did not at a constant. We see that those transitions to areas of greater deprivation are associated with worse mental health and vice versa. This means that those with CMD are more likely to move to areas of greater deprivation, with this being largest for a move from the second least deprived to the most deprived quintile ( $\mathrm{HR}=1.986,95 \% \mathrm{CI}=1.279$ to 3.082$)$. Those with a lower likelihood of having CMD were associated with a transition between the middle third to the first least deprived quintile ( $\mathrm{HR}=0.678,95 \% \mathrm{CI}=0.468$ to 0.983$)$.

\section{DISCUSSION}

The purpose of this study was to investigate to what extent poor mental health influences selective migration. The analyses showed that overall those with poor mental health were more likely to move to areas of higher

Table 2 Number of transitions between Welsh Index of Multiple Deprivation quintiles (1=least deprived, $5=$ most deprived)

\begin{tabular}{lllrrr}
\hline \multirow{2}{*}{ From } & \multicolumn{1}{l}{ To } & \multicolumn{1}{l}{} \\
\cline { 2 - 6 } & $\mathbf{1}$ & $\mathbf{2}$ & \multicolumn{1}{c}{$\mathbf{3}$} & \multicolumn{1}{c}{$\mathbf{4}$} & \multicolumn{1}{c}{$\mathbf{5}$} \\
\hline 1 & 644 & 175 & 326 & 430 & 325 \\
\hline 2 & 164 & 760 & 395 & 597 & 462 \\
3 & 341 & 444 & 1751 & 1043 & 864 \\
4 & 429 & 571 & 1045 & 3119 & 1509 \\
5 & 322 & 428 & 925 & 1484 & 2615 \\
\hline
\end{tabular}


deprivation. In terms of health selection, mental health is an important factor. Overall, those who moved are more likely to move to areas of less deprivation, and this effect is much greater among those without a common mental disorder, supporting the healthy migrant effect.

The present findings provide support for the health selection hypothesis, which suggest residing in or moving to areas of higher deprivation is a consequence of poor mental health. This then leads to an increased concentration of those with poor mental health in areas of higher deprivation. This effect remains after controlling for several social and economic factors and physical health status. Previous research has highlighted physical health as a driver of health selection and this study adds to the growing body work implicating mental health in this as well. The present study suggests mental health has an effect over and above that of physical health.

Our results suggest differences may arise as individuals with poor mental health migrate into more deprived geographies and those with better mental health migrate out. While international migration has been considered from a health perspective, too little empirical work has addressed the relationships between health and migration within countries. Longitudinal data on individuals are critical to understanding the actual changes in mental health in different geographies, allowing assessment of changes in mental health in those that remain in the same communities and those that migrate. Migration must also be considered when assessing the impact of population health measures to improve mental health. Successful interventions may result in migration out of areas to more affluent areas while migration of those with poor mental health into more deprived areas may confound accurate assessment. The relationship between poor mental health and movement into more deprived communities should be considered when allocating funding for mental health interventions to different areas. More deprived areas requiring funding address mental health issues in their current residents and may require resources to address a steady stream of individuals with poor mental health that may migrate into that locality.

The main strength of the study is that we have representative baseline survey data on 10892 subjects covering a comprehensive range of topics including socioeconomic position, health status and perceptions of neighbourhood at two different time points with 15 years' follow-up. Using the NWIS anonymised linking fields split file method, ${ }^{3435}$ we have achieved record-linkage to the WDS to ascertain migration status. Several limitations should be considered. First, we are dependent on the validity of the administrative datasets used to derive the migration events and we were constrained to using these datasets as supplied by the data owners. Second, the explanatory variables were measured at two time points when the outcome, residing WIMD category, could vary freely. Therefore, there was potential for misclassification bias, where some subjects will have changed mental health status at time points other than the two waves. However, as status could change in any direction, it is unclear in which direction any bias would operate. Third, as with all surveys non-response plays a part, and with two waves this is multiplicative. Those responding tend to be healthier and wealthier, but higher rates of attrition from some subgroups are an unavoidable part of population surveys. Finally, only $93.4 \%$ of the total sample were able to be matched confidently to the WDS data, however, given that we are using administrative data for this analysis it is likely that these are random, so the risk of selection bias is probably quite low.

\section{CONCLUSION}

Our findings provide evidence for mental health selection and that the pattern of the effect is like that of physical health. Those moving to an area of greater deprivation were more likely to experience common mental health disorders. Therefore, any potential funding targeted at areas of higher deprivation should consider the fluidity

Table 3 Likelihoods (HRs with $95 \%$ Cls, bold $=\mathrm{p}<0.05$ ) of having a common mental health disorder (scoring $<60$ on $\mathrm{MHI}$ ) by transitions (moves) between WIMD quintiles (1=least deprived, 5=most deprived) adjusted for gender, age group (in 10-year bands), neighbourhood cohesion, social class, employment status, housing tenure, Council Tax band, poverty status and physical health

\begin{tabular}{|c|c|c|c|c|c|c|}
\hline & \multirow[b]{3}{*}{ WIMD } & \multicolumn{5}{|l|}{ To } \\
\hline & & \multicolumn{2}{|l|}{ Least deprived } & \multicolumn{2}{|l|}{ Middle } & \multirow{2}{*}{$\begin{array}{l}\text { Most deprived } \\
5\end{array}$} \\
\hline & & 1 & 2 & 3 & 4 & \\
\hline \multirow{2}{*}{ From } & 2 & 0.84 (0.49 to 1.45$)$ & & 1.23 (0.84 to 1.80$)$ & $1.35(0.97$ to 1.87$)$ & 1.98 (1.27 to 3.08$)$ \\
\hline & 3 Middle & $0.67(0.46$ to 0.98$)$ & 0.88 (0.64 to 1.20$)$ & & $1.47(1.16$ to 1.86$)$ & 1.71 (1.31 to 2.23$)$ \\
\hline
\end{tabular}

The unadjusted likelihoods are presented in online supplementary table S1.

$\mathrm{MHI}$, Mental Health Inventory; WMID, Welsh Index of Multiple Deprivation. 
of the population. The findings suggest that demand for services may be greater than originally thought due to the flow of those with poor mental health into areas of higher deprivation.

\section{Twitter Mark A Bellis @markabellis}

Contributors GG undertook the analysis and wrote the first draft. AG coded the changes in migration status. DF helped design, undertake and interpret the analysis, LT extracted the data and coded all the events, SP, ARD and MAB conceived the study. All authors provided comments at each draft and approved the final manuscript.

Funding Funding for this work was received from Public Health Wales NHS Trust as part of a report on migration and health. Support for the report was also received from the National Centre for Population Health and Wellbeing Research (NCPHWR). The eCATALYST multiagency dataset and the baseline survey was supported by the Wales Office of Research and Development (SCC99/1/105 and R00/1/017). The follow-up survey was supported by a Welsh Assembly Government/Medical Research Council Health Research Partnership Award (H07-3-030), and the electronic cohort is supported by a National Institute for Social Care and Health Research Welsh Assembly Government Translational Health Research Platform Award (TPR08-020).

Competing interests None declared.

Patient consent for publication Not required.

Ethics approval Ethical approval for the baseline survey was received from the former Gwent Local Research Ethics Committee and for the wave 2 survey from the SE Wales Research Ethics Committee. The electronic record-linked cohort study received approval from the independent Information Governance Review Panel, whose membership includes representatives from a range of government, regulatory and professional agencies in Wales, established to assess all applications to anonymously record-link datasets within the SAlL databank.

Provenance and peer review Not commissioned; externally peer reviewed.

Data availability statement Data may be obtained from a third party and are not publicly available. The electronic cohort is securely stored and maintained on the Secure Anonymised Information Linkage (SAIL) databank at Swansea University Medical School. The authors welcome general enquiries and ideas for new collaborations. Readers with an interest in further details should contact Professor Shantini Paranjothy, Principal Investigator.

Open access This is an open access article distributed in accordance with the Creative Commons Attribution Non Commercial (CC BY-NC 4.0) license, which permits others to distribute, remix, adapt, build upon this work non-commercially, and license their derivative works on different terms, provided the original work is properly cited, appropriate credit is given, any changes made indicated, and the use is non-commercial. See: http://creativecommons.org/licenses/by-nc/4.0/.

\section{ORCID iD}

Giles Greene http://orcid.org/0000-0001-9326-8740

\section{REFERENCES}

$1 \mathrm{Kim}$ D. Blues from the neighborhood? Neighborhood characteristics and depression. Epidemiol Rev 2008;30:101-17.

2 Mair C, Diez Roux AV, Galea S. Are neighbourhood characteristics associated with depressive symptoms? A review of evidence. J Epidemiol Community Health 2008;62:940-6, 8 p following 946.

3 Stewart-Brown S, Samaraweera PC, Taggart F, et al. Socioeconomic gradients and mental health: implications for public health. $\mathrm{Br} J$ Psychiatry 2015;206:461-5.

4 Boyle P, Norman P. Migration and health. A companion to health and medical geography, 2009: 346-74.

5 Pearce JR, Dorling D. The influence of selective migration patterns among smokers and nonsmokers on geographical inequalities in health. Ann Assoc Am Geogr 2010;100:393-408.

6 Popham F, Boyle PJ, O'Reilly D, et al. Selective internal migration. Does it explain Glasgow's worsening mortality record? Health Place 2011;17:1212-7.

7 Kanbur R, Rapoport H. Migration selectivity and the evolution of spatial inequality. J Econ Geogr 2005;5:43-57.

8 Brown D, O'Reilly D, Gayle V, et al. Socio-demographic and health characteristics of individuals left behind in deprived and declining areas in Scotland. Health Place 2012;18:440-4.
9 Darlington-Pollock F, Norman P. Examining ethnic inequalities in health and tenure in England: a repeated cross-sectional analysis. Health Place 2017;46:82-90.

10 Jongeneel-Grimen B, Droomers M, Stronks K, et al. Migration and geographical inequalities in health in the Netherlands: an investigation of age patterns. Int J Public Health 2013;58:845-54.

11 Tunstall H, Shortt NK, Pearce JR, et al. Difficult life events, selective migration and spatial inequalities in mental health in the UK. PLoS One 2015;10:e0126567.

12 Norman P, Boyle P. Are health inequalities between differently deprived areas evident at different ages? A longitudinal study of census records in England and Wales, 1991-2001. Health Place 2014;26:88-93

13 Gartner A, Farewell D, Greene G, et al. Does selective migration alter socioeconomic inequalities in mortality in Wales?: a recordlinked total population e-cohort study. SSM Popul Health 2018;5:48-54.

14 Abraído-Lanza AF, Dohrenwend BP, Ng-Mak DS, et al. The Latino mortality paradox: a test of the "salmon bias" and healthy migrant hypotheses. Am J Public Health 1999;89:1543-8.

15 Dhadda A, Greene G. 'The healthy migrant effect' for mental health in England: Propensity-score matched analysis using the empiric survey. J Immigr Minor Health 2018;20:799-808.

16 Woodhead C, Aschan L, Lynskey MT, et al. Exploring evidence for a prospective relationship between common mental disorder and meeting residential mobility preferences. Health Place 2015;32:19-28.

17 Boyle P, Norman P, Rees P. Does migration exaggerate the relationship between deprivation and limiting long-term illness? A Scottish analysis. Soc Sci Med 2002;55:21-31.

18 Wilding S, Martin D, Moon G. Place and preference effects on the association between mental health and internal migration within great Britain. Health Place 2018;52:180-7.

19 Dodd W, Humphries S, Patel K, et al. Determinants of internal migrant health and the healthy migrant effect in South India: a mixed methods study. BMC Int Health Hum Rights 2017;17:23.

20 Ginsburg C, Bocquier P, Béguy D, et al. Healthy or unhealthy migrants? Identifying internal migration effects on mortality in Africa using health and demographic surveillance systems of the indepth network. Soc Sci Med 2016;164:59-73.

21 Tunstall $\mathrm{H}$, Mitchell R, Pearce J, et al. The general and mental health of movers to more- and less-disadvantaged socio-economic and physical environments within the UK. Soc Sci Med 2014;118:97-107.

22 Kiely KM, Butterworth P. Mental health selection and income support dynamics: multiple spell discrete-time survival analyses of welfare receipt. J Epidemiol Community Health 2014;68:349-55.

23 Bhugra D. Migration and mental health. Acta Psychiatr Scand 2004;109:243-58.

24 Kuo W. Theories of migration and mental health: an empirical testing on Chinese-Americans. Soc Sci Med 1976;10:297-306.

25 Loret de Mola C, Stanojevic S, Ruiz P, et al. The effect of rural-tourban migration on social capital and common mental disorders: PERU MIGRANT study. Soc Psychiatry Psychiatr Epidemiol 2012;47:967-73.

26 Swinnen SG, Selten J-P. Mood disorders and migration metaanalysis. The British Journal of Psychiatry 2007;190:6-10.

27 Brimblecombe N, Dorling D, Shaw M. Migration and geographical inequalities in health in Britain. Soc Sci Med 2000;50:861-78.

28 Chen W, Hall BJ, Ling L, et al. Pre-migration and post-migration factors associated with mental health in humanitarian migrants in Australia and the moderation effect of post-migration stressors: findings from the first wave data of the BNLA cohort study. Lancet Psychiatry 2017;4:218-29.

29 Fellmeth G, Fazel M, Plugge E. Migration and perinatal mental health in women from low- and middle-income countries: a systematic review and meta-analysis. BJOG: Int J Obstet Gy 2017;124:742-52.

30 Fortuna LR, Álvarez K, Ramos Ortiz Z, et al. Mental health, migration stressors and suicidal ideation among Latino immigrants in Spain and the United States. Eur Psychiatry 2016;36:15-22.

31 Curtis S, Setia MS, Quesnel-Vallee A. Socio-geographic mobility and health status: a longitudinal analysis using the National population health survey of Canada. Soc Sci Med 2009;69:1845-53.

32 Welsh Government. Welsh index of multiple deprivation (WIMD), 2019. Available: http://gov.wales/statistics-and-research/welshindex-multiple-deprivation/?Lang=en

33 Fone DL, Dunstan F, White J, et al. Cohort profile: the Caerphilly health and social needs electronic cohort study (E-CATALyST). Int $J$ Epidemiol 2013;42:1620-8.

34 Ford DV, Jones KH, Verplancke J-P, et al. The SAIL Databank: building a national architecture for e-health research and evaluation. BMC Health Serv Res 2009;9:157. 
35 Lyons RA, Jones $\mathrm{KH}$, John G, et al. The SAIL databank: linking multiple health and social care datasets. BMC Med Inform Decis Mak 2009;9:3.

36 Ware JE, Kosinski M, Dewey JE, et al. SF-36 health survey: manual and interpretation guide Quality Metric Inc 2000.

37 Kelly MJ, Dunstan FD, Lloyd K, et al. Evaluating cutpoints for the MHI-5 and MCS using the GHQ-12: a comparison of five different methods. BMC Psychiatry 2008;8:10.

38 Buckner JC. The development of an instrument to measure neighborhood cohesion. Am J Community Psychol 1988;16:771-91.

39 Fone DL, Farewell DM, Dunstan FD. An ecometric analysis of neighbourhood cohesion. Popul Health Metr 2006;4:17.
40 StataCorp L. STATA 15 [Computer software]. College Station, TX: StataCorp LP, 2018.

41 R Core Team. R Foundation for Statistical Computing; Vienna, Austria: 2014. In: R: a language and environment for statistical computing 2018, 2013.

42 Kalbfleisch JD, Lawless JF. The analysis of panel data under a Markov assumption. J Am Stat Assoc 1985;80:863-71.

43 Jackson C, Jackson MC. Package 'msm' 2019.

44 Lou W, Wan L, Abner EL, et al. Multi-state models and missing covariate data: Expectation-Maximization algorithm for likelihood estimation. Biostat Epidemiol 2017;1:20-35. 